\title{
An inference of the wading depths of the cranes in wintering wetlands through photographic sampling: a case study of black-necked cranes (Grus nigricollis) in Caohai Wetland, China
}

\author{
Xue Gou $\cdot$ Xijiao Sun · Romaan Hayat Khattak • \\ Ruisha Zhao • Yao Hu Canshi Hu \\ Mingming Zhang $\cdot$ Haijun Su
}

Received: 23 July 2021 / Accepted: 31 January 2022 / Published online: 11 February 2022

(C) The Author(s) 2022

\begin{abstract}
Several overwintering crane species like Black-necked cranes (Grus nigricollis) mainly depends on wetlands for foraging or roosting, preferring stable water depths. Understating the wading depths of cranes is a pressing concern for the better management of wetlands and robust conservation of the overwintering cranes populations. Yet, practically it is very difficult to precisely measure the wading depths due to several limitations like, inaccessibility and sampling difficulties. In the current study a sample of 1288 wading photographs of cranes, based on the constancy of proportion of tibiotarsus to tarsometatarsus was taken in Caohai wetland situated in the Northwest Guizhou Province of southwest China. Caohai Wetland is the biggest overwintering wetland
\end{abstract}

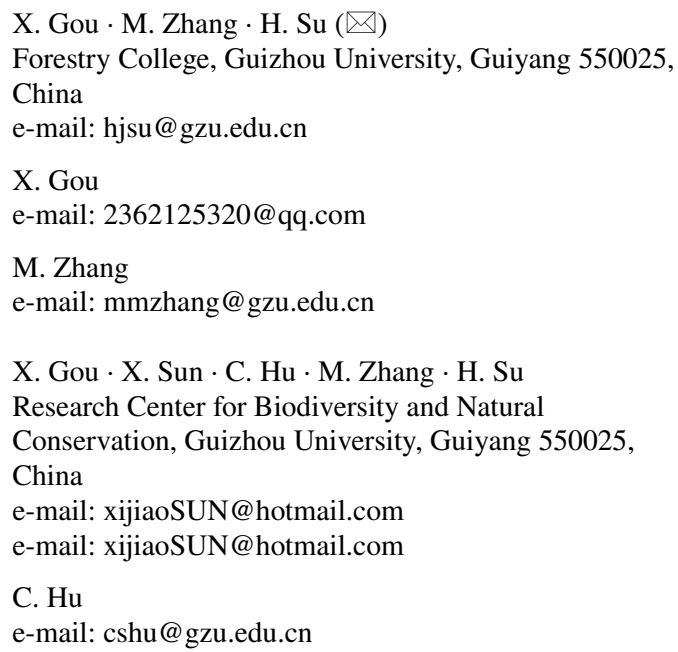

around the world, and a very promising area to infer the exact ranges of wading depths of these cranes. The ratio of tibiotarsus to tarsometatarsus of the cranes standing on the lands and the ratio of tibiotarsus to the rest of tarsometatarsus of the cranes standing in water were measured; to infer the projection depths of the part of tarsometatarsus submerged in water, which was used to calculate the accurate depth range of the cranes by comparing with the referenced values. According to the results, $89.92 \%$ of individuals preferred the water depths from $(0-20] \mathrm{cm}$, $76.11 \%$ preferred $(0-10] \mathrm{cm} \%$ while water depths for $49.04 \%$ individuals was $(0-5] \mathrm{cm}$. Thus we conclude that the Black-necked Cranes prefer a depth range

\section{Sun}

Forestry Bureau of Buyi and Miao Minorities Autonomous Prefecture, Xingyi 562400, China

R. H. Khattak

College of Wildlife and Protected Areas, Northeast

Forestry University, Harbin 150040, China

e-mail: romaanktk@gmail.com

R. Zhao - Y. Hu

School of Mathematics and Statistics, Guizhou University,

Guiyang 550025, China

e-mail: Zruis0204@hotmail.com

$\mathrm{Y} . \mathrm{Hu}$

e-mail: yhu1@gzu.edu.cn

C. $\mathrm{Hu}$

College of Life Sciences, Guizhou University,

Guiyang 550025, China 
of $(0-10] \mathrm{cm}$. This water depth may be relative to the swamps around the lake, which are very important foraging and roosting sites for cranes, For better habitat management, we strongly recommend paying special attention to swamps with specific water depth ranges, particularly when the water level changes.

Keywords Overwintering black-necked cranes . Habitat selection - Wading depth · Wetland water level $\cdot$ Caohai wetland of Guizhou

\section{Introduction}

The Black-necked Cranes (Grus nigricollis) is the only crane species in the world that lives on the plateau for their whole lives, and their life history is inseparable from the wetlands ( $\mathrm{Li}$ 2014). Being large wading birds, the Black-necked Cranes often feed and perch in shallow waters, especially in wintering wetlands Shallow wetlands are the most important habitats necessary for their fixed night roosting activities. Coupled with many factors like food conditions, leg lengths, and walking resistance, water depths have a direct effect on their behavior and habitat utilization (Sun et al. 2018). The Black-necked Cranes have certain selectivity to the depths of inhabited waters. In some studies, the depths of the roosting sites of the cranes have been t estimated. Hu et al. (2002) found that the water depths of the roosting sites of the overwintering Black-necked Cranes in Dashanbao Wetland in Yunnan Province were about $30 \mathrm{~cm}$. Liu et al. (2008) reported that the Black-necked Cranes in Napahai Wetland in Yunnan Province preferred lakeshores or stream confluences with the water depths higher than $10 \mathrm{~cm}$ for night roosting. He et al. (2011) and Li et al. (2017) believed that of water depth of the selected site by the Black-necked Cranes in Napahai wetland was less than $30 \mathrm{~cm}$. However, non among all aforementioned studies are based on detailed sampling data. Subject to the sampling difficulties in assessing cranes or the standing points, authentic reports based on accurate and convincing research are scarce.

It is generally believed that the ratio of femur or tibiotarsus to tarsometatarsus is constant and interspecific (Zhang et al. 2008). We hypothesize that adult Black-necked cranes have a constant tibiotarsus $(A)$ to tarsometatarsus $(B)$ ratio. Based on it, we calculated the ratio of the tibiotarsus to the part of tarsometatarsus higher than the water level accurately as possible as we could, then we could infer the length of the part of tarsometatarsus submerged in the water through the real measurements (Wu et al. 2016). The photographic sampling was used to calculate this accurate ratio according to the principle of geometric morphometry, and it is known that the shape of the proportion of all parts of an organism will not change due to the changes of sizes (Klingenberg 2016). In this way, the photographs of the Blacknecked Cranes can be fully used, although many photographs were taken by different distances and angles, the ratio of tibiotarsus to tarsometatarsus shall be nearly invariable. In this paper, This hypothesis was tried to be tested and the exact depth range of wadding of wintering the Black-necked cranes was calculated ultimately.

\section{Study area}

The current study 2018 was conducted at Caohai (N 26 $47^{\prime} \sim 26^{\circ} 52^{\prime}$, E $104^{\circ} 10^{\prime} \sim 104^{\circ} 20^{\prime}$ ) Wetland Weining, Guizhou China (Fig. 1). This wetland is located in the hinterland of Wumeng mountains in the central part of Yunnan-Guzhou plateau and is a typical representative of low altitude plateau wetlands in China, with an elevation range of 2200-2250 m Above Sea Level (ASL). The total area of Caohai is $120 \mathrm{~km}^{2}$ with $25 \mathrm{~km}^{2}$ of water. The elevation of the normal water level is $2171.7 \mathrm{~m}$, and the maximum water depth is $5.0 \mathrm{~m}$. Caohai belongs to the subtropical plateau monsoon climate, with the yearly average temperature of $10.9{ }^{\circ} \mathrm{C}$ and the coldest monthly average (January) temperature of $2.1^{\circ} \mathrm{C}$. Every winter, more than 80 species of waterbirds and 80,000 individual birds live in Caohai Wetland (Zhang et al. 2014). This wetland is surrounded by gentle undulating topography, relatively with slight variation in elevation. Seven sites at Caohai lake and the surrounding agricultural lands have been declared by the local government as roosting sites for Black-necked cranes. Every year by the end of October and the start of November the Black-necked cranes start migrating from their breeding grounds area at Ruoergai Marsh in northern Sichuan to Caohai for wintering, and leave again in March. From 2010 to 2021, about 2000 black-necked cranes have been wintering in 


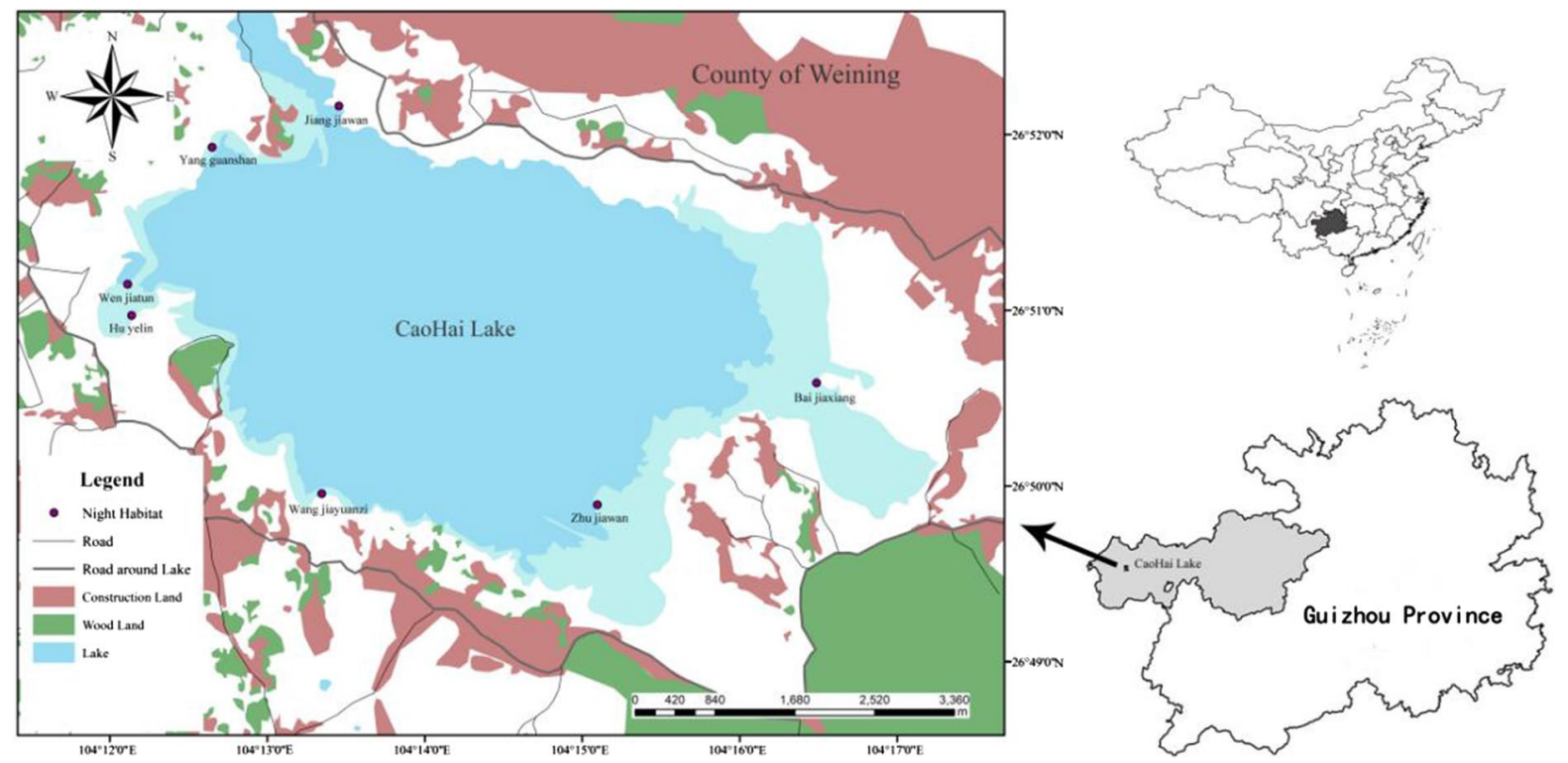

Fig. 1 Land use map of black-necked crane roosting sites and cultivated land area in Caohai Wetland

Caohai every year, and the photos measured more than 1200 black-necked cranes.

\section{Research methods}

Data acquisition

\section{Photographic sampling and measurements}

Black-necked cranes were randomly photographed using (EOS 7D Mark II) for 4 years (winter 2016-2019) at Caohai. Photographs were taken throughout the whole winter including early-winter (11th of November to 31st of December, EW), midwinter (1st of January to 20th of February, MW), and late-winter (21st of February to 31st of March, LW). After ensuring the birds was foraging on land or wading in the water, photographs were taken by normal standing posture and lateral views. All the photographs were taken in daylight. We also collected One hundred photographs taken by other bird-watchers in the same area, and a total of 1288 photographs were collected. 405 photographs were taken for birds standing on land and 883 photographs for wading in water.

\section{Photographs processing}

AutoCAD Software (Version 2007; Autodesk Corporation, USA) was used by the same manipulators to accurately measure the lengths of parts of these adult Black-necked Cranes on the pictures, including the lengths of tarsometatarsus (Length of B: from the joints of tarsometatarsus and claw to the joints of tibiotarsus and tarsometatarsus when the cranes were standing on land; Length of $\mathrm{B}_{1}$ : from the joints of tibiotarsus and tarsometatarsus to the water surface when the cranes were wading in water) and the projection length of tibiotarsus (Length of $\mathrm{A}$ or $A_{l}$ : from the joints of tibiotarsus and tarsometatarsus to the margin of thigh covered with feather) (see Fig. 1).

\section{Acquirement of actual data for verification}

The actual physical measurement data were mainly derived from literature records and real measurements. A total of 10 accurate measurements of tarsometatarsus of cranes $\left(a_{1}\right)$ were collected (Table 1). About the sexual dimorphism, the statistical analysis of 15 Black-necked Cranes was collected from Caohai from 1987 1989 by Guizhou Provincial Institute for Animal Husbandry and Veterinary Medicine, which showed that the most average values of the measurements between males and females of the Black-necked Cranes were 
Table 1 The actual measurement data of the black-necked cranes

\begin{tabular}{|c|c|c|c|c|c|c|c|}
\hline Individual & Gender & Weight/g & Body length/cm & Mouth peak/cm & Wing length/cm & Tail length/cm & $\begin{array}{l}\text { Tarsometa- } \\
\text { tarsus }\left(a_{1}\right. \\
) / \mathrm{cm}\end{array}$ \\
\hline 01 & $\sigma^{\pi}$ & 4880 & 116.6 & 11.9 & 58.9 & 22.8 & 24.2 \\
\hline 02 & $\sigma^{\lambda}$ & 3850 & 114.0 & 11.4 & 58.5 & 22.5 & 23.1 \\
\hline 03 & $\hat{0}$ & 5360 & 120.0 & 12.4 & 63.5 & 23.1 & 25.3 \\
\hline 04 & $q$ & 5230 & 118.1 & 11.6 & 56.1 & 22.0 & 23.6 \\
\hline 05 & 우 & 5000 & 116.1 & 11.5 & 54.0 & 21.8 & 23.8 \\
\hline 06 & 우 & 5550 & 120.0 & 11.7 & 58.2 & 22.1 & 23.3 \\
\hline 07 & 우 & 3500 & 113.0 & 12.0 & 57.0 & 22.0 & 23.0 \\
\hline 08 & q & 5270 & 112.0 & 12.5 & 57.0 & 34.0 & 23.0 \\
\hline 09 & $\hat{0}$ & 4500 & 116.0 & 11.5 & 57.0 & 25.0 & 25.0 \\
\hline 10 & $\hat{\sigma}$ & Defect & Defect & Defect & Defect & Defect & 25.0 \\
\hline
\end{tabular}

Source: Samples No. 1-4 were from (Li and Li 2005); Samples No. 5-6 were from (Wu et al. 1986); Samples No. 7-9 were from (Xiao et al. 1999); sample No. 10 was from the specimens of the Black-necked Cranes kept by Bureau of Xishui National Nature Reserve in Guizhou Province

not significantly different. Except for the peak lengths $(\mathrm{P}<0.05)$, there was no significant difference in body weights, body lengths, wing lengths, tail lengths and tarsometatarsus $(\mathrm{P}>0.05)(\mathrm{Li}$ and $\mathrm{Li}$ 2005). Therefore, while using the actual measurements the influences of gender differences were not considered. The real measurement data were used to calculate and verify the proportions of the tibiotarsus and tarsometatarsus on the photographs.

\section{Statistical methods}

\section{Inferencing formula}

Initially, the pictures of the cranes standing on land were used to analyze the density function distribution and its constancy ratio of tibiotarsus $(A)$ and tarsometatarsus $(B)$, which is the premise for inferring the projected length of tarsometatarsus submerged in water. According to the formula, can be called as land ratio and a wading ratio, and when the density functions of both are similar, our general assumption is established, and the projection value of water depth can be furtherly calculated. As shown in Fig. 2, The rationale also was illustrated (Wu et al. 2016). The formula is:

$\frac{A}{B}=\frac{A_{1}}{B_{1}+r} .$, and $:=\frac{A_{1} B}{A}-B_{1} ., W D=a_{1} \times r$

(Note: $A, B, A_{1}, B_{l}$, and $r$ are all projection length values.no unit dimension for this projection.)[Where, $A$ and $B$ are the projection length of tibiotarsus and
Fig. 2 Measurements on the tibiotarsus $\left(A_{I}\right.$ or $\left.\mathrm{A}\right)$ and tarsometatarsus $\left(\mathrm{B}_{1}\right.$ plus the part submerged in water, or B) of black-necked cranes when wading in water and standing on land from pictures
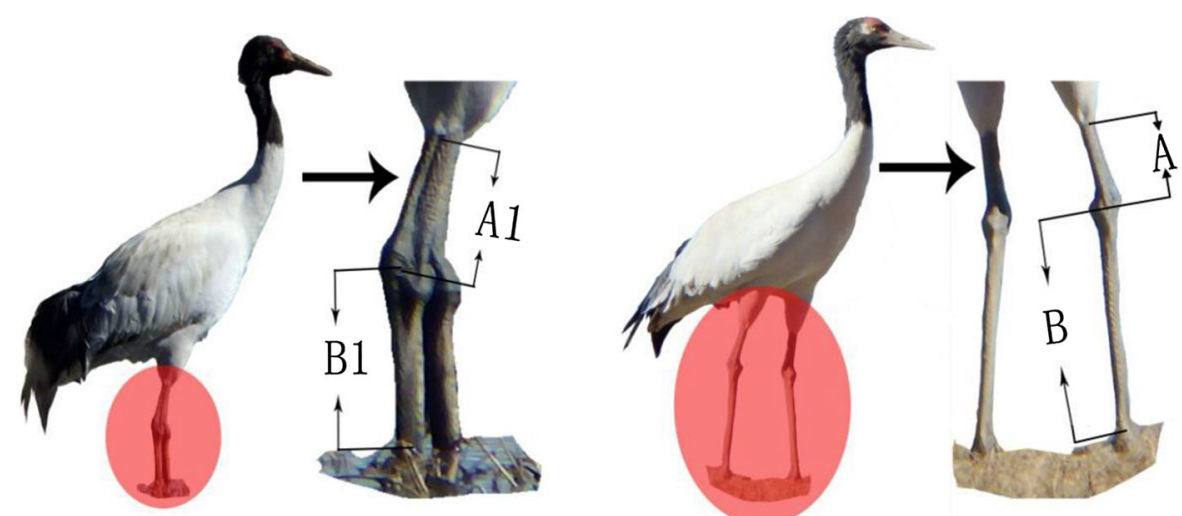
tarsometatarsus of black-necked Crane standing on land, respectively; $A_{l}$ and $B_{l}$ is the projection lengths of the tibiotarsus and tarsometatarsus of black-necked Crane standing in water, respectively. $r$ is the length projection of the tarsometatarsus submerged of blacknecked Crane in water; $a_{1}$ is the actual length of tarsometatarsus (Table 1); WD is the Water Depth].

\section{Data analysis}

Kolmogorov-Smirnov was used to test whether the ratios of land ratio and wading ratio are normally distributed, respectively $\left(\mathrm{H}_{0}\right.$ : the total distribution of samples comes from the normal distribution, a significant level was set $\mathrm{a}=0.001$ ), then the respective ratio histograms were drawn, and the kernel density estimation curve (Kernel Density Estimation (KDE) was used to compare with the normal distribution probability curve (Gauss fitting curve) (GFC) to determine the sampling method. we used bootstrap resampling to calculate the land ratio of 405 samples and wading radio of 883 samples to verify the reasonableness of the general hypothesis formula according to the comparison between the two curves. Then, the land ratio, $A_{1}$ And $B_{1}$ obtained by bootstrap resampling were separately used to calculate the wading depth projection values $r$ in the formula. The 10 actual measured values $a_{l}(\mathrm{~cm})$ of tarsometatarsus that we collected were used to calculate the $r$ according to the formula $\mathrm{WD}=a_{1} \times r$. Similarly, 10 actual samples were used for bootstrap sampling with 883 pictured samples had been repeated 883 times to figure out 883 wading depths $W D(\mathrm{~cm})$. Finally, the frequencies and ranges of these results of wading depths were analyzed to determine the exact range of water depths of wading of the Black-necked Cranes.

All analytical calculations and drawings were done using R Software (Xue et al. 2007; R Core Development Team, 2019).

\section{Results and analysis}

Land ratio $\left(\frac{A}{B}\right)$ and wading ratio $\left(\frac{A_{1}}{B_{1}+r}\right)$

The Kolmogorov-Smirnov test showed that the land ratio was by following per under normal distribution $(\mathrm{n}=405, \mathrm{P}=0.0062>\mathrm{a})$, it is found that there is a certain difference between the kernel density estimation curve and the probability density curve of normal distribution (Fig. 3). Therefore, it is necessary to continue to resample the land ratio. The right deviation of land ratio in the curve was significantly improved and closer to the fitting estimation curve of normal distribution after bootstrap resampling. Therefore, bootstrap resampling was used for subsequent sampling, namely, it was more reasonable to use the bootstrap-resampled land ratio to infer the projection $r$ for exploring the real wading depth.

As shown in, the comparison between land ratio and wading ratio revealed that they both were matched on the forms of curves (Fig. 4). These results verified that the formulas used in our study could be reasonable and in line with actual situations.

Wading depth projection values $r$

According to the frequency (Table 2), 627 wading depth projection values can be obtained within (0-10], reaching $71.01 \%$ of the total samples.

Amongst all ranges, (0-1] accounts for 59.68\%, which means that most of the water depth projection values are in the range of $(0-10]$.

The actual wading depths (WD) of the black-necked cranes

Bootstrap sampling had been carried out and repeated 883 times after introducing the 10 actual values of tarsometatarsus to obtain the actual wading depths. However, the results of $W D>50 \mathrm{~cm}$ were excluded; because in reality, there is an extremely low possibility of the cranes standing in water more than $50 \mathrm{~cm}$ depth. As shown as most of the results of $W D$ were concentrated at intervals less than $30 \mathrm{~cm}$ (Fig. 5) (Table 3).

Statistics further revealed that $95.24 \%$ of the total samples $(\mathrm{n}=883)$ involved were within $(0,30) \mathrm{cm}$. And, $88.67 \%(\mathrm{n}=783)$ were less than $20 \mathrm{~cm}$. If more specifically, $75.31 \%(\mathrm{n}=665)$ were amongst $(0,10] \mathrm{cm}$, while nearly half $(47.23 \%)$ preferred to wade in the water with depths less than $5 \mathrm{~cm}$ (Table 4).

Learn from Table 5. (0-20] Range of wading depth $W D(\mathrm{~cm})$ The percentage of total water depth is relatively large (0-10], A total of 665 values, accounting for $75.31 \%$ of the total wading depth, that is, most of the wading depth. $W D(\mathrm{~cm})$ All in (0-10] Scope. In addition (0-10] In the range, (0-5] The number is the largest, reaching $47.23 \%$ of the total water depth. 
(a)

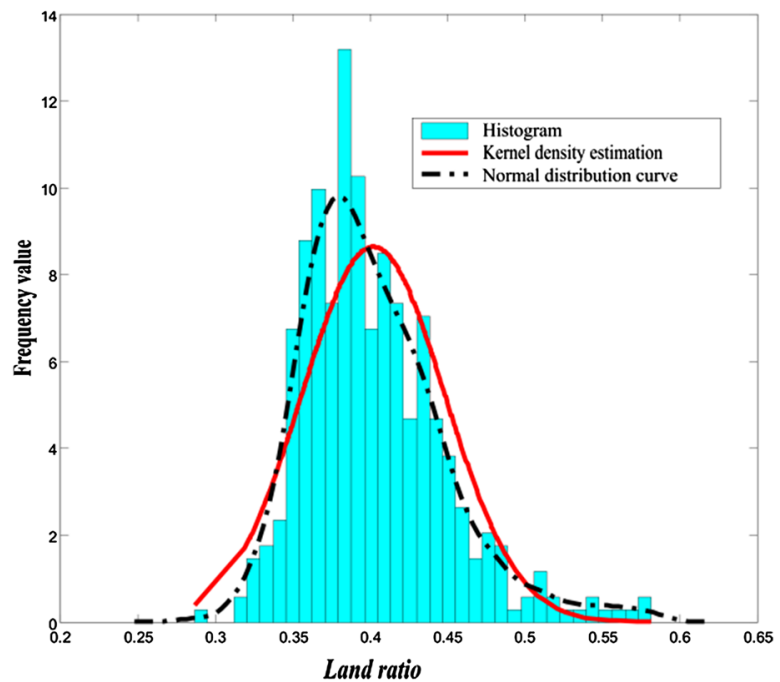

(b)

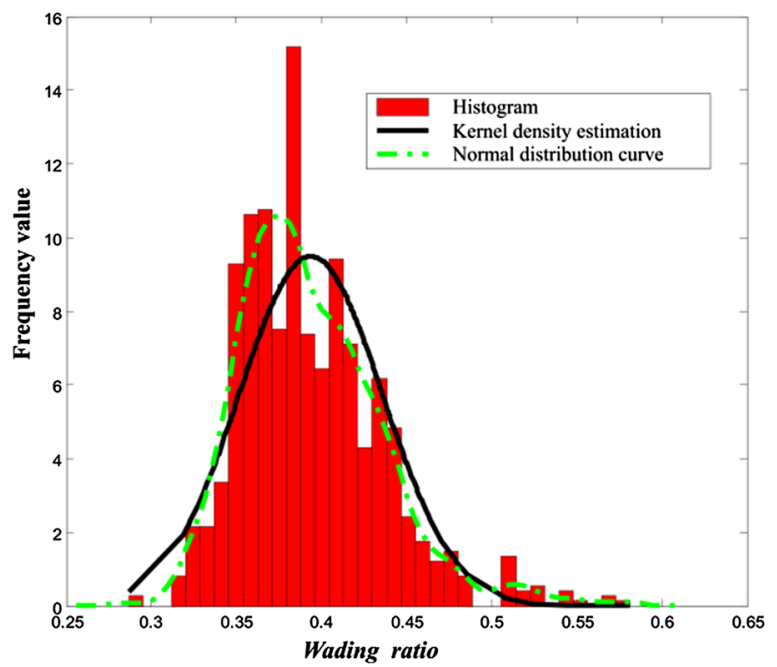

(d)
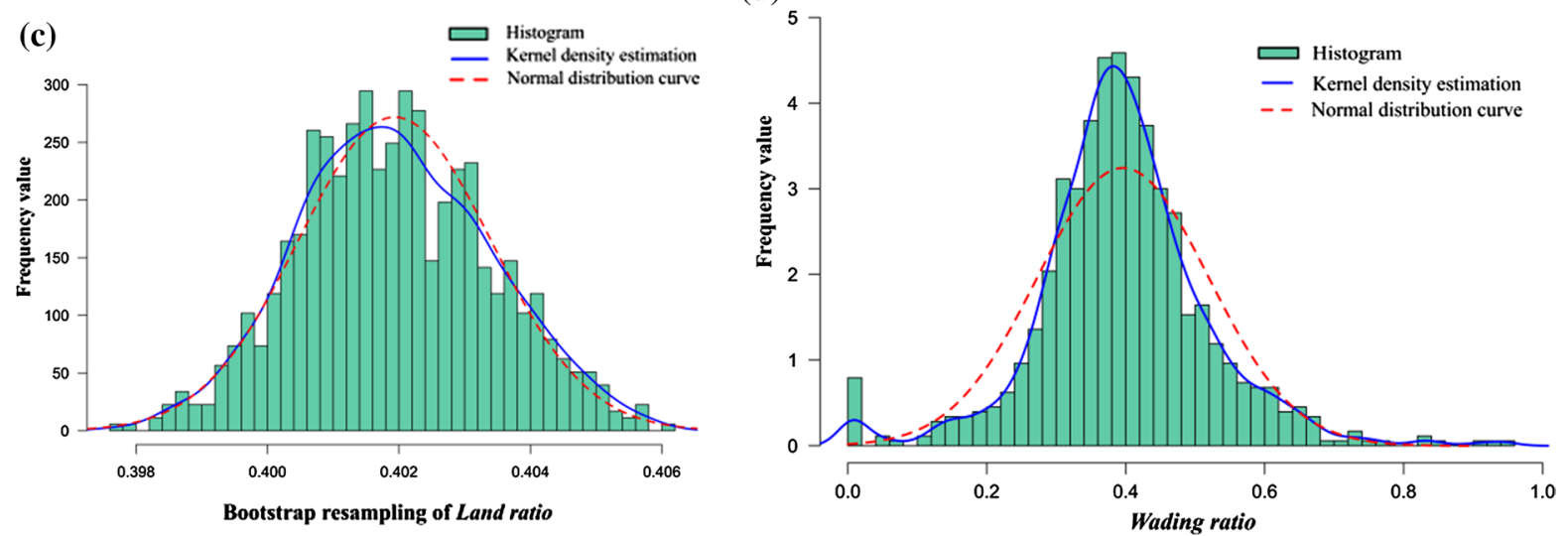

Fig. 3 a Normality test of Land Ratio $\left(\frac{A}{B}\right)$ of 405 samples. b Normality test of $\left(\frac{A_{1}}{B_{1}}\right)$ of 883 samples. c Bootstrap resampling of Land Ratio $\left(\frac{A}{B}\right)$ of 405 samples. d Curves of wading ratio $\left(\frac{A_{1}}{B_{1}+r}\right)$ calculated using bootstrap resampled Land Ratio for $r$

\section{Discussion}

Nondestructive or non-disturbance sampling is always recommended for investigating animal ecology (Richards et al. 2014). In our study, the ratio of tibiotarsus and tarsometatarsus when the cranes were standing on land and the ratio of tibiotarsus and tarsometatarsus submerged in water were verified using the photographic sampling, and both ratios obeyed the normal distributions and had similar density functions, which represented that the overall inference hypothesis in our study was reasonable and feasible. When the land ratio has been calculated, it was very critical for sequent calculations about how to get the wading depth projection value $r$.

Our results showed that the Black-necked Cranes preferred to choose the shallow water areas with the water depth less than $20 \mathrm{~cm}$, especially less than $10 \mathrm{~cm}$ and they nearly do not prefer the water depths higher than $30 \mathrm{~cm}$. Infield investigation in Caohai, the Black-necked Cranes almost never drowned their whole tarsometatarsus when choosing wading habitats. This is similar to the field observation results from Dashanbao and Napahai in Yunnan ( $\mathrm{Li}$ and $\mathrm{Li} 2005$ ), as well as similar to the overwintering Black-necked Cranes found on the sides of lakes, reservoirs, or river shoals in Tibet (Lei et al. 2012). Similarly with the other crane species, for example, the 
Fig. 4 Comparison of straight and fitting curves between dry land and sampling water intake ratio

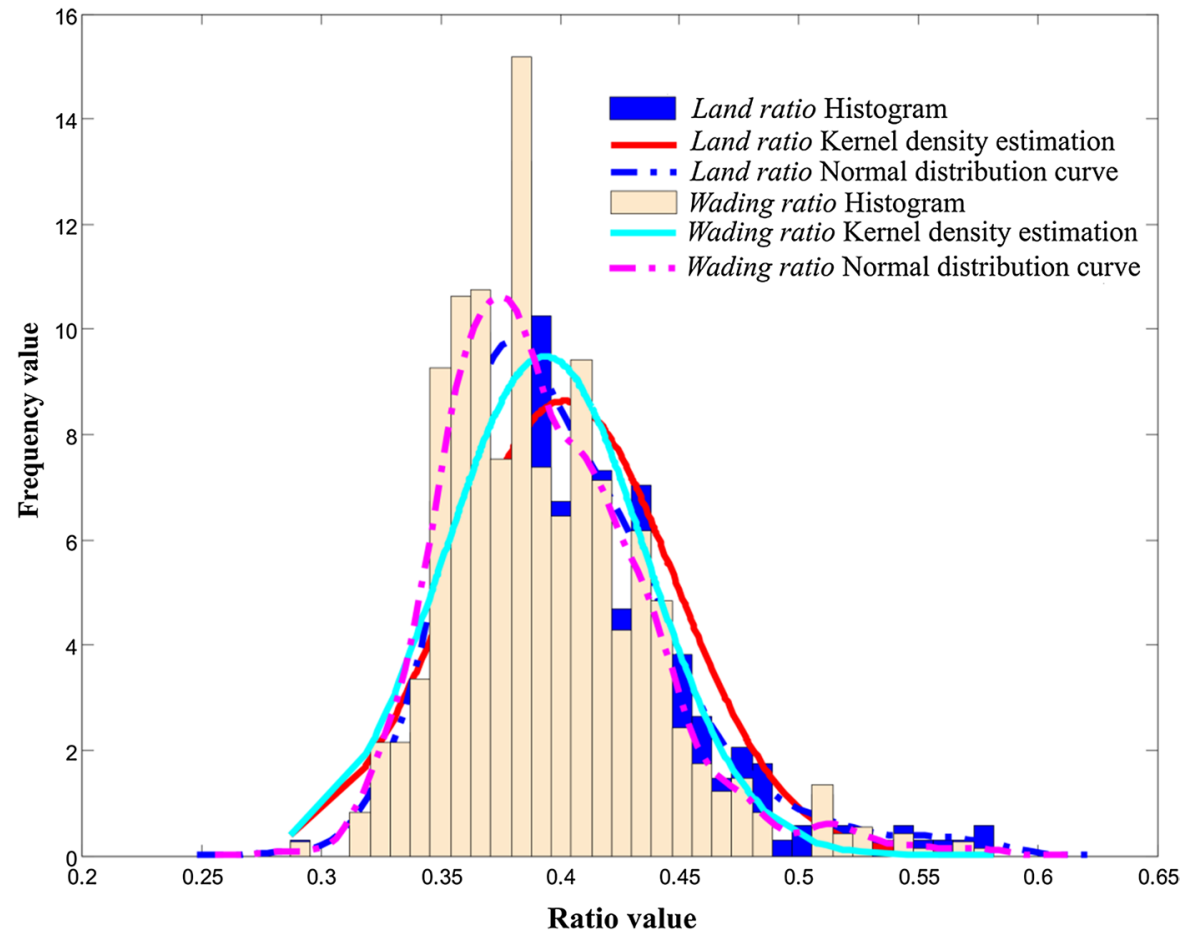

Ratio value
Table 2 Frequency table of total frequency of wading depth projection $r$ (no unit dimension for this projection)

\begin{tabular}{lcl}
\hline Interval & Frequency & $\begin{array}{l}\text { Relative } \\
\text { frequency } \\
(\%)\end{array}$ \\
\hline$(0-10]$ & 627 & 71.01 \\
$(10-20]$ & 16 & 1.81 \\
$(20-30]$ & 14 & 1.59 \\
$(30-40]$ & 29 & 3.28 \\
$(40-50]$ & 21 & 2.38 \\
$(50-60]$ & 21 & 2.38 \\
$(60-70]$ & 31 & 3.51 \\
$(70-80]$ & 21 & 2.38 \\
$(80-90]$ & 19 & 2.15 \\
$(90-100]$ & 17 & 1.93 \\
$(100-200]$ & 53 & 6.00 \\
$(200-300]$ & 10 & 1.13 \\
$(300-400]$ & 3 & 0.34 \\
$(400-413]$ & 1 & 0.11 \\
\hline
\end{tabular}

Siberian Cranes (Grus leucogeranus), a closely related species to the Black-necked Cranes, overwinter in Shahu and Poyang Lake. Wu et al. (2013) estimated that $58 \%$ of the white cranes moved in the water depths of 5-27 cm and the Siberian Cranes were also mainly in shallow

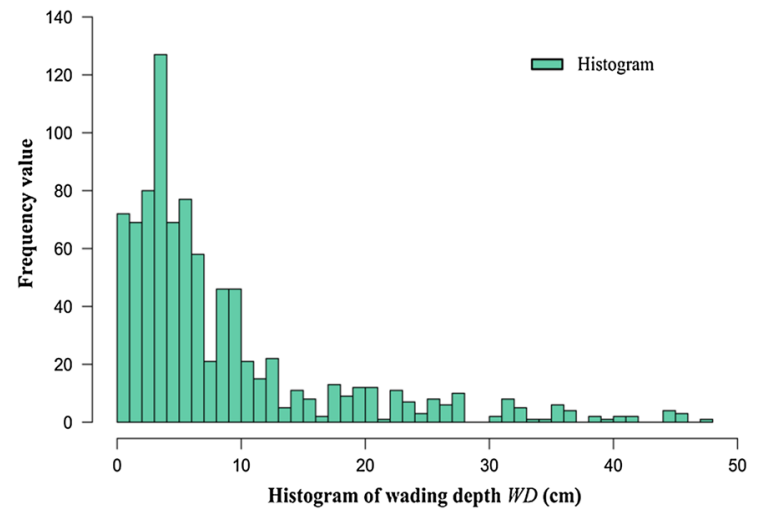

Fig. 5 Histogram of wading depth $W D(\mathrm{~cm})$

water with depths below the tarsometatarsus (Wu et al. 2013). He et al. (2002) observed that small groups or families of Siberian Cranes were mainly scattered in some scattered shallow water pools with the depth of the water mostly $2 \sim 10 \mathrm{~cm}$ in Momoge Nature Reserve, Jilin Province, China, but for large flocks of cranes, the water depth was relatively deeper, ranging from 10 to $30 \mathrm{~cm}$ (He et al. 2002). Lv et al. (2007) reported that the wading water depth of the Red-crowned Crane (Grus japonensis) was generally below $30 \mathrm{~cm}$ and few cranes were wading 
Table 3 Frequency table of wading depth projection values amongst $(0,10]$

\begin{tabular}{lrl}
\hline Interval & Frequency & $\begin{array}{l}\text { Relative } \\
\text { frequency } \\
(\%)\end{array}$ \\
\hline$(0-1]$ & 527 & 59.68 \\
$(1-2]$ & 58 & 6.57 \\
$(2-3]$ & 20 & 2.27 \\
$(3-4]$ & 9 & 1.02 \\
$(4-5]$ & 3 & 0.34 \\
$(5-6]$ & 1 & 0.11 \\
$(6-7]$ & 2 & 0.23 \\
$(7-8]$ & 5 & 0.57 \\
$(8-9]$ & 2 & 0.23 \\
$(9-10]$ & 0 & 0 \\
\hline
\end{tabular}

Table 4 Frequency distribution of wading depth $(W D)$ of the black-necked cranes in Caohai Wetland

\begin{tabular}{lcll}
\hline Interval $(\mathrm{cm})$ & Frequency & $\begin{array}{l}\text { Relative frequency } \\
(\%)\end{array}$ \\
\hline$(0-10]$ & 665 & 75.31 & \\
$(10-20]$ & 118 & 13.36 & \\
$(20-30]$ & 58 & 6.57 & \\
$(30-40]$ & 30 & 3.40 & 47.23 \\
$(40-50]$ & 12 & 1.36 & 28.09 \\
$(0-5]$ & 417 & & 8.38 \\
$(5-10]$ & 248 & & 4.96 \\
$(10-15]$ & 74 & & \\
$(15-20]$ & 44 & & \\
\hline
\end{tabular}

Table 5 Frequency table of wading depth $W D$ at (0-20]cm

\begin{tabular}{lcl}
\hline Interval $(\mathrm{cm})$ & Frequency & $\begin{array}{l}\text { Relative } \\
\text { frequency } \\
(\%)\end{array}$ \\
\hline$(0,5]$ & 433 & 47.23 \\
$(5,10]$ & 239 & 28.09 \\
$(10,1]$ & 86 & 8.38 \\
$(15,20]$ & 36 & 4.96 \\
\hline
\end{tabular}

at the higher depth of $30 \mathrm{~cm}$ (Lv et al. 2007), and the research results of the common cranes (Grus grus) and the Sandhill Cranes (Grus canadensis) (JM et al. 2004; Folk 1990) were in agreement with our results. All the aforementioned results were derived from subjective estimation; yet, our results are based on a relatively big sample size and fine derivations.

Field observations in our study showed that the Blacknecked Cranes overwintering in Caohai Lake mainly preferred to stay in the lacustrine regions, sedge meadows, shallow meadows, barren grasslands, cornfields, and vegetable fields (Wu et al. 2020). Shallow swamps and sedge meadows, provides a vast range of plant communities that cranes can consume, In addition to an abundant supply of snail and small fishes that can serve as rich protein sources for these birds (Wu and $\mathrm{Li}$ 1985; Li 1999). Therefore, the Black-necked Cranes were observed to frequently prefer wading in these shallow areas with a water depth of $(0-10) \mathrm{cm}$.

Currently, the authorities are planning to raise the water level of Caohai from 2171.7 to $2173 \mathrm{~m}$, to expand the water surface area up to $33 \mathrm{~km}^{2}$ (Ran et al. 2017). The overall water level will be raised by more than $1 \mathrm{~m}$, which will drastically affect the current distribution of foraging and roosting sites of the Black-necked Cranes. During the increased and high water levels, it becomes difficult for cranes to locate the food. Our study in this regard provides reliable guidance to better maintain the water levels and habitat management for the Blacknecked cranes at Caohai and the other overwintering sites. Based on the results of the current study we strongly recommend maintaining stable water levels and predicting the formation of new suitable overwintering habitats. Furthermore, we believe slow adjustments of water level can gradually enhance the cranes' adaptability; and ultimately the Blacked-necked cranes' habitats can be better protected and managed, both quantitatively and qualitatively.

Author contributions $\mathrm{XG}$ and $\mathrm{HS}$ conceived the study, XG and XS implemented the field surveys and collected the data, $\mathrm{XG}, \mathrm{RZ}, \mathrm{CH}$ and $\mathrm{YH}$ anlysed the data, XG wrote the manuscript. HS supervised the research and provided multiple revisions of the writing. Romaan $\mathrm{HK}, \mathrm{CH}$ and $\mathrm{MZ}$ conducted research method guidance for the article. All authors read and approved the final manuscript.

Funding This paper is financially supported by following projects: National Natural Science Foundation of China (NSFC) (31860610, 31400353); Provincial Key Science and Technology Project of Guizhou ([2016]3022-1); Provincial Science and Technology Plan of Guizhou ([2014]7682; [2019]2842; [2019]1068). 
Data availability The datasets generated and/or analysed during the current study are available from the corresponding author upon reasonable request.

\section{Declarations}

Conflict of interest The authors declare that they have no competing interests.

Ethical approval Ethics approval and consent to participate. The investigations comply with the current laws of China, where they were performed.

\section{Consent for publication Not applicable.}

Open Access This article is licensed under a Creative Commons Attribution 4.0 International License, which permits use, sharing, adaptation, distribution and reproduction in any medium or format, as long as you give appropriate credit to the original author(s) and the source, provide a link to the Creative Commons licence, and indicate if changes were made. The images or other third party material in this article are included in the article's Creative Commons licence, unless indicated otherwise in a credit line to the material. If material is not included in the article's Creative Commons licence and your intended use is not permitted by statutory regulation or exceeds the permitted use, you will need to obtain permission directly from the copyright holder. To view a copy of this licence, visit http://creativecommons.org/licenses/by/4.0/.

\section{References}

Folk MJTT (1990) Sandhill crane roost site characteristics in the North Platte river valley Nebraska USA. J Wildl Manag 54:480-486

He C, Song Y, Lang H, Li H, Sun X (2002) Migratory dynamics of Siberian crane and environmental conditions at its stopover site. Biodivers Sci 10:286-290

He P, Kong D, Liu Q, Yu H, Zhao J, Yang X (2011) Roosting-site characteristics of wintering black-necked cranes (Grus nigricollis) at Napahai. Yunnan Zool Res 32:150-156

Hu J, Wu J, Dang C, Zhong X, Dao M (2002) Study on the animal foods of wintering Black-necked Cranes(Grus nigricollis) at Dashanbao reserve, Zhaotong Yunnan. J Yunnan Univ (natural Sciences Edition) 06:459-461

JM A (2004) Common cranes (Grus grus) and habitat management in holm oak dehesas of Spain. Biodivers Conserv 13:2015-2025

Klingenberg PC (2016) Size, shape, and form: concepts of allometry in geometric morphometrics. Dev Genes Evol 226:113-137

Lei G, Sang J, Zheng Z (2012) Site and behavior of sleep of Grus nigricollis in Kazi water reserve of Linzhou, Tibet. J West China For Sci 41:93-97

Li FS (1999) Foraging habitat selection of the wintering black-necked Cranes in Caohai, Guizhou, China. Chin Biodivers 4:257-262

Li FS (2014) IUCN Black-necked crane (Grus nigricollis) conservation plan. Zool Res 35:3-9. https://doi.org/10.11813/j. issn.2095-8137.2014.s1.0003
Li ZM, Li FS (2005) Black-necked crane research. Shanghai Science and Technology Education Press, China, Shanghai

Li J, Hu J, Luo H, Jia H (2017) Interference Intensity of human activities on wintering habitats of black-necked crane in Napahai wetlands and their patterns. Wetl Sci 15:343-350

Liu Q, Yang X, Zhu J, Zhao J, Yu H (2008) Flock of blacknecked crane wintering at Napahai nature reserve. Zool Res 29:553-560

Lv SC (2007) Quantitative distribution in night of red-crowned crane on the artificial wetland during wintering stage. Chin J Wildl 28:11-13

R Core Team (2019) $R$ : a language and environment for statistical computing. R Foundation for Statistical Computing, Vienna, Austria

Ran JC, Meng WP, Su HJ, Zhang MM (2017) The impact of environmental problems on black- necked crane(Grus nigricollis) and the management strategies at Caohai Wetland, Guizhou, China. Chin J Wildl 38:35-39

Richards NL, Hall SW, Harrison NM et al (2014) Merging wildlife and environmental monitoring approaches with forensic principles: application of unconventional and non-invasive sampling in eco- pharmacovigilance. J Forensic Res. https:// doi.org/10.4172/2157-7145.1000228

Sun, X, Zhang, M, Hannah, L, Hu, CS, Su, HJ (2018) Field observations on the behavior of wintering Black-necked cranes (Grus nigricollis) at roosting sites in Caohai, Guizhou. Chin J Zool 2: 180-190. https://doi.org/10.1359/j. cjz.201802003

Wu ZK (1986) The avifauna of Guizhou. Guizhou people's Publishing House China, Guiyang

Wu Z, Li R (1985) A preliminary study on the overwintering ecology of black-necked crenes (Grus nigricollis). Acta Ecol Sin 5:73-78

Wu J, Li F, James B (2013) Numerical distribution of Siberian cranes and their relation to food and water depth in Sha $\mathrm{Hu}$ at Poyang Lake, China. Wetl Sci 11:305-312

Wu Q, He F, Su L, Zhu J, Zou H (2016) The effect of measurement method on recorded water depths used by wetland grallatores. Chin J Wildl 37:346-350

Wu D, Hu C, Zhang M, Li Z, Su H (2020) Foraging habitat selection of overwintering black-necked cranes in the farming area surrounding the Caohai Wetland, Guizhou Province China. Avian Res 11(1):74-82

Xiao F, Zhang Z, Zhao J, Zhou X, Lu Y (1999) Anatomical observation of black-necked crane. J Cap Norm Univ (Natural Science Edition) 20:72-76

Xue Y, Chen L P (2007) Statistical modeling and R software. Tsinghua University Press, Beijing, China

Zhang YG, Li ZH, Tian XY (2008) Hind limb segmentand locomotion in birds: length proportion characteristics and functions. Sichuan J Zool 27:497-505

Zhang HB, Su HJ, Liu W, Li ZM, Zhang MM (2014) Relationship of community structure of main waterfowl with habitat in Caohai national nature reserve in winter. J Ecol Rural Environ 30:601-607

Publisher's Note Springer Nature remains neutral with regard to jurisdictional claims in published maps and institutional affiliations. 